\title{
Effective Sensory Modality Activating an Escape Triggering Neuron Switches during Early Development in Zebrafish
}

\author{
Tsunehiko Kohashi, Natsuyo Nakata, and Yoichi Oda \\ Division of Biological Sciences, Graduate School of Science, Nagoya University, Nagoya 464-8602, Japan
}

\begin{abstract}
Developing nervous systems grow to integrate sensory signals from different modalities and to respond through various behaviors. Here, we examined the development of escape behavior in zebrafish [ $45-170 \mathrm{~h}$ postfertilization (hpf)] to study how developing sensory inputs are integrated into sensorimotor circuits. Mature fish exhibit fast escape upon both auditory/vestibular (AV) and head-tactile stimuli. Newly hatched larvae, however, do not respond to AV stimuli before $75 \mathrm{hpf}$. Because AV-induced fast escape in mature fish is triggered by a pair of hindbrain neurons known as Mauthner (M) cells, we studied functional development of the M-cell circuit accounting for late acquisition of $\mathrm{AV}$-induced escape. In fast escape elicited by head-directed water jet, minimum onset latency decreased throughout development ( $5 \mathrm{~ms}$ at $45-59 \mathrm{hpf}, 3 \mathrm{~ms}$ after $75 \mathrm{hpf}$ ). After $75 \mathrm{hpf}$, lesioning the otic vesicle (OV) to eliminate AV input resulted in loss of short-latency $(<5 \mathrm{~ms})$ fast escape, whereas ablation of the sensory trigeminal ganglion $(\mathrm{gV})$ to block head-tactile input did not. Before 75 hpf, however, fast escape persisted after OV lesion but disappeared after $\mathrm{gV}$ ablation. Laser ablation of the $\mathrm{M}$-cell and $\mathrm{Ca}^{2+}$ imaging of the $\mathrm{M}$-cell during escape demonstrated that $\mathrm{M}$-cell firing is required to initiate short-latency fast escapes at every developmental stage and further suggest that head-tactile input activates the M-cell before $75 \mathrm{hpf}$, but that after this point $\mathrm{AV}$ input activates the M-cell instead. Thus, a switch in the effective sensory input to the M-cells mediates the acquisition of a novel modality for initiating fast escape.
\end{abstract}

\section{Introduction}

Through nervous system development, animals expand their ability to respond to various sensory stimuli and acquire a wide range of sensory-evoked behaviors. Most studies have approached this issue by focusing on the development of circuits from sensory organs to higher brain regions (Allendoerfer and Shatz, 1994; Rubel et al., 1998; Katz and Crowley, 2002; Daw, 2006). Attempts to relate developmental steps in sensory circuits to the behaviors they generate are, however, more challenging because of the need to understand the development of a complete behavioral pathway to motor output. Fast escape in zebrafish is an ideal system to overcome this difficulty because, in addition to the advantages of using zebrafish in developmental biology, the principle circuit for fast escape has been identified from sensory neurons to motor neurons (for review, see Fetcho, 1991; Zottoli et al., 1995).

Fast escape in mature fish is triggered by aversive stimuli via activation of a Mauthner (M) cell, one of two bilateral giant re-

\footnotetext{
Received Dec. 10, 2011; revised March 3, 2012; accepted March 7, 2012.

Author contributions: T.K. and Y.O. designed research; T.K. and N.N. performed research; T.K. and N.N. analyzed data; T.K. and Y.O. wrote the paper.

This work was supported by Grants-in-Aid for Scientific Research (KAKENHI 12053246 and 17023029 to Y.0.) and by the Global Centers of Excellence Program "Advanced Systems-Biology: Designing The Biological Function" from the Japanese Ministry of Education, Culture, Sports, Science, and Technology. We thank Drs. B.A. Carlson and M. Tanimoto for their careful reading of this manuscript and Drs. H. Okamoto, H. Takeda, and K. Horikawa and the Zebrafish National Bioresource Project of Japan for providing transgenic zebrafish.

The authors declare no competing financial interests.

Correspondence should be addressed to Tsunehiko Kohashi or Yoichi Oda, Division of Biological Science, Graduate School of Science, Nagoya University, Furo, Chikusa, Nagoya 464-8602, Japan. E-mail: kohashi-@@bio.nagoyau.ac.jp; oda@bio.nagoya-u.ac.jp.

DOI:10.1523/JNEUROSCI.6169-11.2012

Copyright $\odot 2012$ the authors $\quad 0270-6474 / 12 / 325810-11 \$ 15.00 / 0$
}

ticulospinal neurons (RSNs) in the hindbrain (Zottoli, 1977; Eaton et al., 1981). Here, we studied how developing sensory input is integrated into behavior by investigating the functional development of the $\mathrm{M}$-cell sensorimotor circuit in zebrafish. Advanced larvae [after $\sim 80 \mathrm{~h}$ postfertilization (hpf) at $28.5^{\circ} \mathrm{C}$; scaled from $\sim 100 \mathrm{hpf}$ at $25^{\circ} \mathrm{C}$ according to Kimmel et al. (1995)] exhibit fast escape in response to auditory/vestibular (AV) and touch stimuli, whereas newly hatched larvae (45-70 hpf) can escape from touch but not from AV stimulation (Kimmel et al., 1974). In advanced larvae (>120 hpf), Kohashi and Oda (2008) found that $A V$ input preferentially elicits fast escape through $\mathrm{M}$-cell firing (M-escape), whereas head-tactile input triggers kinematically similar fast escape that occurs through the firing of other hindbrain RSNs rather than M-cells (non-M-escape). Thus, one might presume that tactile-evoked non-M-escape develops first in zebrafish and that the M-cells are not involved in escape initiation until AV input becomes sufficient to activate them.

Previous studies, however, have indicated that head-tactile stimuli activate M-cells to trigger fast escape in newly hatched zebrafish. Mechanical stimuli applied to the head at 39-77 hpf evoked an extracellular field potential, presumably from the M-cells, followed by trunk movement (Eaton et al., 1977). Additionally, M-cells before hatching already receive input from trigeminal sensory afferents innervating the head skin (18 hpf; Kimmel et al., 1990), extend their axons throughout the length of the spinal cord (by 50 hpf; Eaton and Farley, 1973), and synapse with spinal neurons (Jontes et al., 2000).

When and how is AV input integrated into the developing escape circuit? When does the developing M-cell actually begin to play its role in fast escape? To address these questions, we per- 

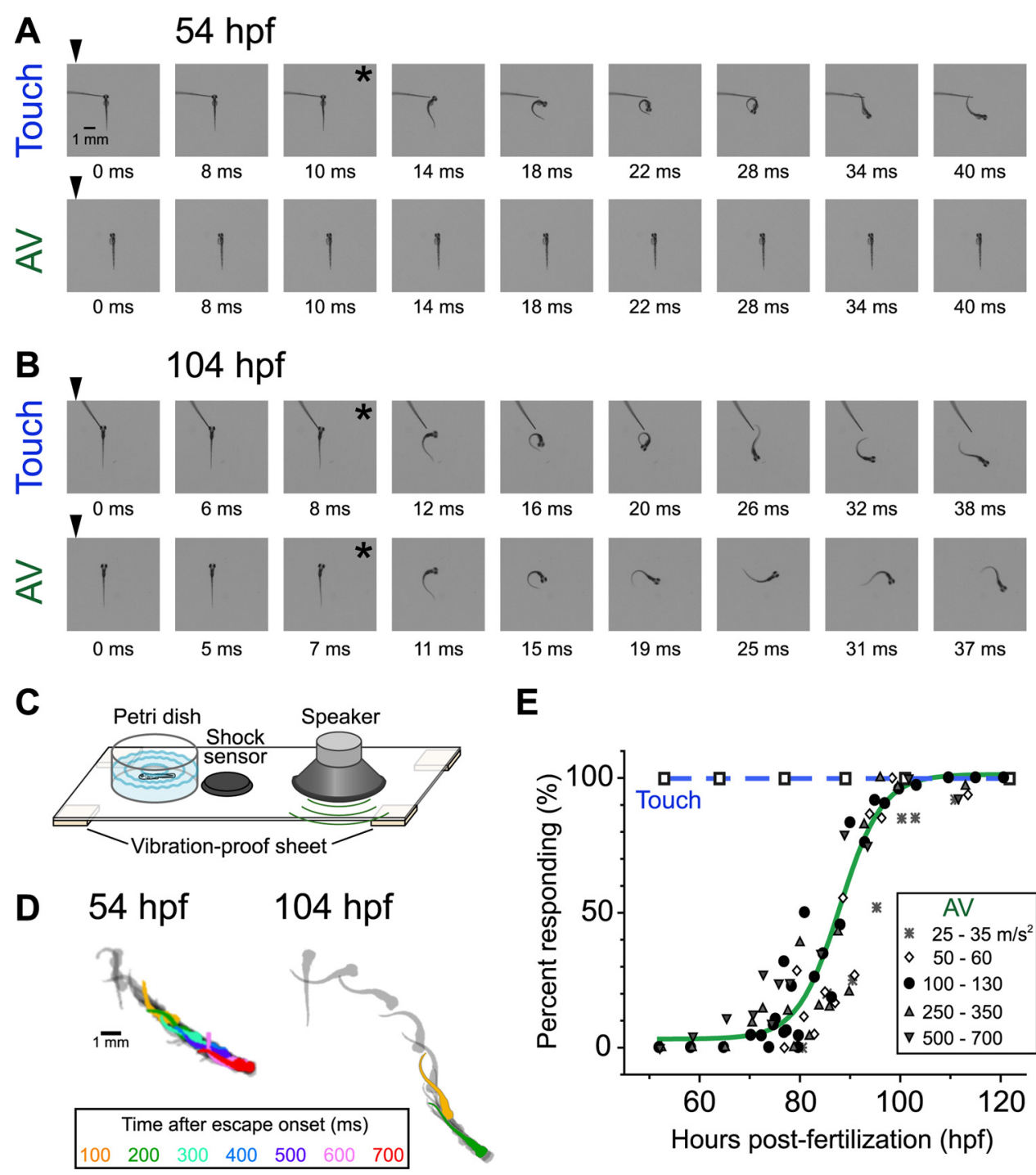

E

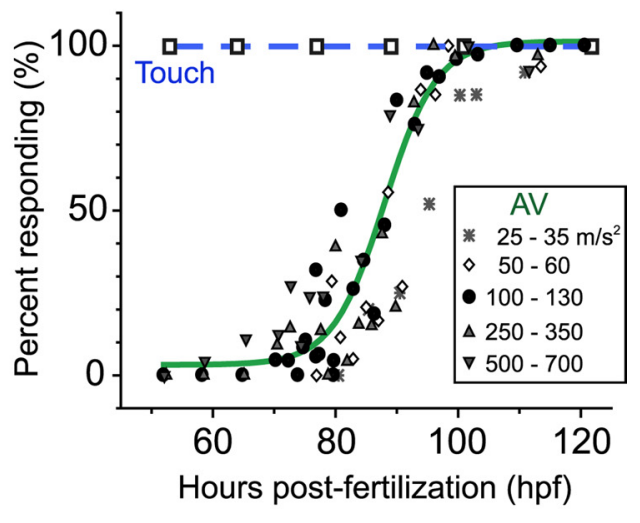

Figure 1. Development of escape behavior evoked by head-touch or AV stimulation. $\boldsymbol{A}, \boldsymbol{B}$, Fast escape of zebrafish larvae at $54(\boldsymbol{A})$ and $104(\boldsymbol{B})$ hpf in response to head touch with hair (top rows) or AV stimulation generated by a loudspeaker (bottom rows; peak stimulus intensity, $100 \mathrm{~m} / \mathrm{s}^{2}$ ). Fast escapes were elicited at $54 \mathrm{hpf}$ by touch stimulus only but at $104 \mathrm{hpf}$ by either touch or AV stimulus. Time after stimulus onset (arrowheads; $0 \mathrm{~ms}$ ) is denoted. Behavioral onset is indicated by asterisks. C, Schematic illustration of the apparatus for AV stimulation. For details, see Materials and Methods. D, Superimposed silhouettes of a newly hatched (left, $54 \mathrm{hpf}$ ) larva and an advanced (right, $104 \mathrm{hpf}$ ) larva during fast escape, captured every $20 \mathrm{~ms}$ after behavioral onset. Every 100 $\mathrm{ms}$, silhouettes are shown in different colors (inset). E, Percentage of larvae escaping (ordinate) in response to head-touch (open squares connected by a blue dotted line) or AV stimulation at various intensities (see key) is plotted against hours postfertilization (abscissa). Data associated with AV stimulus of $100-130 \mathrm{~m} / \mathrm{s}^{2}$ (filled circles) were fitted with the Boltzmann equation with a half-maximal time at $88 \mathrm{hpf}$ (green line). Twenty to 36 larvae were tested for each point.

formed $\mathrm{Ca}^{2+}$ imaging of the M-cell during escape and examined the effects of lesioning certain sensory inputs or the M-cell itself in larvae at various stages from newly hatched to advanced. Our results suggest that the sensory modality effective for eliciting $\mathrm{M}$-escape switches from head-tactile to AV input during early development and that M-cell firing is necessary to initiate fast escape with minimal latency both before and after this switch.

\section{Materials and Methods}

Animals. We used post-hatch larvae (45 to $170 \mathrm{hpf}$ ) of wild-type zebrafish (Danio rerio) as well as three transgenic strains, all of which were maintained at $28.5^{\circ} \mathrm{C}$ and staged according to standard procedures (Westerfield, 2007). The transgenic lines were $z$ CREST2-isl1:GFP, which expresses green fluorescent protein (GFP) in the sensory trigeminal ganglion (gV) neurons (Uemura et al., 2005), and Tol026 and Tol056, which express GFP in the M-cells (Satou et al., 2009; Tanimoto et al., 2009). Experiments on larvae were performed at room temperature (27- $29^{\circ} \mathrm{C}$ ). All procedures were performed in compliance with the guidelines approved by the Animal Care and Use Committee of Nagoya University.

Stimulation of unrestrained larvae. To observe escape behaviors in unrestrained zebrafish, larvae were kept in a Petri dish (35 $\mathrm{mm}$ in diameter) filled with $10 \% \mathrm{HBSS}$ (in mм: $13.7 \mathrm{NaCl}, 0.54 \mathrm{KCl}, 0.025 \mathrm{Na}_{2} \mathrm{HPO}_{4}$, $0.044 \mathrm{KH}_{2} \mathrm{PO}_{4}, 0.13 \mathrm{CaCl}_{2}, 0.10 \mathrm{MgSO}_{4}$, and $\left.0.42 \mathrm{NaHCO}_{3}, \mathrm{pH} 7.2\right)$ at a depth of $\sim 4 \mathrm{~mm}$. Escape response was elicited by tactile stimulation of the head with an eyebrow hair or by AV stimulation via a custom-made apparatus (modified from Satou et al., 2009) (Fig. 1C). The apparatus consisted of a loudspeaker (SC5.9 8006; VISATON) screwed to an acrylic plate $(100 \times 180 \times 2.0 \mathrm{~mm})$ onto which the Petri dish containing the larvae was tightly glued with dental wax. Each corner of the plate was placed on a vibration-proof sticky sheet (Sigma Gel; Geltec). Sinusoidal waves (2.0 cycles of $500 \mathrm{~Hz}$ sine waveform), generated by a function generator (Wave Factory 1941; NF Corporation) and amplified by an audio amplifier, were delivered to the loudspeaker. The stimulus waveform was monitored using a shock sensor module (PIEZOTITE PKS1- 
4A1; Murata Manufacturing) attached to the plate. Output voltage of the shock sensor was low-pass filtered at $1000 \mathrm{~Hz}$ and converted to acceleration value $\left[4.1 \mathrm{mV} /\left(\mathrm{m} / \mathrm{s}^{2}\right)\right.$, according to data provided by the manufacturer]. Stimulus intensity was measured as the peak acceleration amplitude during vibration.

Semifixed preparation. To observe tail movement during escape with high temporal resolution, the rostral half of a larva was embedded in $3.5 \%$ agar (low-melting-point agarose, gelled at $28^{\circ} \mathrm{C}$; Invitrogen) with its dorsal side up. After the agar had congealed, the chamber was filled with $10 \%$ HBSS and the portion of the tail caudal to the cloaca was exposed. Tail flip was elicited by a pulsed water jet (water pulse) applied every $3-5 \mathrm{~min}$ to the otic vesicle (OV) through a syringe needle (26 gauge; Terumo), the tip of which was held $0.5 \mathrm{~mm}$ away from the head surface by a micromanipulator (MM-200; Narishige). The agar covering the OV was cut to admit the needle. The water pulses were generated by a Picospritzer III (Parker Hannifin) delivering a pressure pulse of $3 \mathrm{~ms}$ in duration. The pressure was kept below 30 psi, which was slightly higher than the minimum value that was required to elicit an escape in every larva we tested ( $25 \mathrm{psi})$. Viability of each fish was monitored by observing fast blood flow within the brain.

Behavioral analysis of fast escape. Behavioral analysis was performed as described previously (Kohashi and Oda, 2008). Briefly, sequential images of the escape response were captured every $1 \mathrm{~ms}$ using a high-speed digital camera (Fastcam Ultima 1024 or Fastcam 1024 PCI; Photoron). Latency was defined as the elapsed time from the stimulus arrival to the beginning of tail movement. For sound stimuli, the stimulus arrival time was defined as the time when the function generator was triggered. For other stimuli, the stimulus arrival time was defined as the time when the stimulus reached the head surface. We defined a behavior starting with latency shorter than $100 \mathrm{~ms}$ as an escape response (Kimmel et al., 1974). The tail flexion angle was measured based on three dots placed on the midline of each fish, at the cloaca (dot 2) and at L/12 rostral (dot 1) and L/6 caudal (dot 3) to dot 2; L represents the distance from the caudal end of the yolk sac to the tip of the tail. Average angular velocity during the 6 $\mathrm{ms}$ after movement onset was defined as the initial angular velocity.

Deprivation of sensory input. To eliminate sensory input from the OV, the otoliths on one side were ablated by intense laser pulses (MicroPoint Laser System; Photonic Instruments) or surgically removed with a fine tungsten needle under anesthesia with $0.01 \% 3$-aminobenzoic acid ethyl ester (MS-222; Sigma-Aldrich) (Kohashi and Oda, 2008). Soon after these fish had recovered from anesthesia, they were able to swim but unable to keep their dorsal sides up; they exhibited poor balance and abnormal rotation. Postlesion testing was performed 2-12 h after the ablation.

The lateral line system was blocked through pharmacological degeneration of the neuromast hair cells. Larvae were immersed in 10\% HBSS containing 300-500 $\mu \mathrm{M}$ neomycin sulfate (Wako Pure Chemical Industries) and incubated (at $28.5^{\circ} \mathrm{C}$ ) for $1 \mathrm{~h}$ as reported previously (Harris et al., 2003). The fish were then rinsed three times quickly in normal $10 \%$ HBSS and returned to an incubator at $28.5^{\circ} \mathrm{C}$. Behavioral tests were performed during the next $3-5 \mathrm{~h}$, before the hair cells started regenerating (Harris et al., 2003). Successful elimination of the lateral line hair cells was verified by staining them through incubation in $10 \%$ HBSS containing DASPEI (0.05\%, 2-[4-(dimethylamino)styryl]- $N$-ethylpyridinium iodide; Invitrogen) for $20 \mathrm{~min}$.

Head-tactile input was eliminated by laser ablation of the $\mathrm{gV}$ neurons using the MicroPoint laser system. Larvae were embedded in agar as in the OV-lesioned group. gV neurons were visualized with GFP fluorescence in the transgenic line $z$ CREST2-isl1:GFP. Laser power was attenuated to the minimum level required to kill each ganglion neuron with a single pulse. Behavioral testing began $2-3 \mathrm{~h}$ after ablation. To evaluate the success of the ablation, the larvae were fixed at $4^{\circ} \mathrm{C}$ in $4 \%$ paraformaldehyde soon after the behavioral tests and stained with the anti-HuC/D primary antibodies (1:500 dilution; Invitrogen) (Kimmel et al., 1990; Sagasti et al., 2005) and an Alexa Fluor 564-conjugated secondary antibody (1:2000 dilution; Invitrogen).

Laser ablation of the $M$-cell. The M-cell was laser ablated under anesthesia with $0.01 \%$ MS-222. For larvae between 45 and $80 \mathrm{hpf}$, one of the paired M-cells expressing GFP in the Tol026 or Tol056 transgenic line was irradiated with 200-300 laser pulses using the MicroPoint laser system
(Burgess and Granato, 2007; Satou et al., 2009). Laser power was kept low so as not to cause bleeding during ablation. Behavioral tests were performed 2-4 h after ablation. Selectivity of ablation was assessed in the Tol026 line by observing the remaining fluorescence in RSNs near the lesioned M-cell (see Fig. 4A). To confirm successful ablation of their $\mathrm{M}$-cells, the larvae were fixed and stained with the monoclonal 3A10 primary antibody (1:10; Developmental Studies Hybridoma Bank) (Hatta, 1992) and an Alexa Fluor 564-conjugated secondary antibody (1:2000 dilution) (see Fig. 4B).

For larvae older than $80 \mathrm{hpf}$, the M-cells were labeled with tetramethyl rhodamine dextran (10,000 molecular weight; Invitrogen) and then laser ablated using a confocal laser scanning system (FV300; Olympus) with a $543 \mathrm{~nm}$ helium-neon laser line as described previously (Liu and Fetcho, 1999; Kohashi and Oda, 2008). Successful ablation was verified when no recovery of fluorescence was observed at the soma of the M-cell. Postlesion behavioral tests were performed $4 \mathrm{~h}$ to $1 \mathrm{~d}$ after the exposure.

Simultaneous monitoring of $M$-cell activity and behavior. The correlation between $\mathrm{M}$-cell activity and escape behavior was assessed by simultaneous $\mathrm{Ca}^{2+}$ imaging of M-cell activity and monitoring of tail flip response in semifixed larva, as described previously in detail (Kohashi and Oda, 2008). In brief, a semifixed larva (at either $64-73$ or 105-170 hpf) in which the M-cells were retrogradely labeled with Oregon Green BAPTA-1 (OGB1) dextran (10,000 molecular weight; Invitrogen) was set on the manipulation stage of a custom-built microscope (based on the BX51WI upright microscope; Olympus). The microscope comprised an upright confocal microscope (FV300 using a $488 \mathrm{~nm}$ argon laser line; objective lens, UMPlanFL 40xW/IR; Olympus) for $\mathrm{Ca}^{2+}$ imaging and a low-magnification (objective lens, XLFluor 2x/340; Olympus) inverted microscope for monitoring tail movements with a high-speed camera (Fastcam Ultima 1024 or Fastcam 1024 PCI; Photoron). The tail of the larva in this semifixed preparation was illuminated with orange light (wavelengths, $590-670 \mathrm{~nm}$ ) that did not interfere with confocal imaging.

OGB1 was injected into the caudal spinal cord (at $\sim 22 \mathrm{nd}$ somite) for larvae at 105-170 hpf, whereas the injection was done rostral to the cloaca (at $\sim 10$ th somite) for larvae at $64-73 \mathrm{hpf}$ because, for unknown reasons, caudal injection resulted in poor labeling in these larvae. Although rostral injection impaired tail movement, the onset latency of trunk musculature contraction rostral to the injection site was the same as in uninjected larvae. In uninjected larvae, the onset latency of trunk contractions was identical to that of tail flips. Fluorescence images of the M-cells during escapes elicited by water pulse were captured at $260 \mathrm{~ms}$ per frame. Relative change in fluorescence of the cell body from the resting intensity $(\Delta F / F)$ was calculated. To evaluate spiking in each cell, the sensoryevoked response was normalized to the antidromically evoked response obtained afterward in the same cell (Kohashi and Oda, 2008; Satou et al., 2009). To induce antidromic action potentials in the $\mathrm{M}$-axon, a bipolar tungsten electrode was placed on the spinal cord rostral to the OGB1 injection site and bipolar pulsed currents ( $80 \mu$ s duration) were delivered through it.

Statistics. Results are presented as the mean \pm SD. Statistical significance was assessed using the Mann-Whitney $U$ test unless otherwise noted.

\section{Results}

\section{Appearance of AV-induced escape during development}

Development of escape was investigated previously in embryonic and larval zebrafish raised at lower temperatures $\left(25-26^{\circ} \mathrm{C}\right)$ (Kimmel et al., 1974; Eaton et al., 1977). Here, we reexamined the time course of AV- or touch-induced escape development using zebrafish raised at $28.5^{\circ} \mathrm{C}$. Newly hatched larvae (45-70 hpf) mostly lay on one side or upside down at rest and rarely swam spontaneously. When the head skin was gently touched with hair, every larva showed an abrupt and rapid whole-body bend away from the stimulus (C-bend) and a subsequent counter-bend as shown in Figure $1 A$ (top), in which the fish was artificially placed dorsal side up for demonstration. The C-bend and counter-bend are typically observed at the initiation of fast escape in adult teleosts (for review, see Domenici and Blake, 1997). The touch- 
induced body bend was followed by a series of side-to-side flexions typically lasting from hundreds of milliseconds to seconds (Fig. 1 D, left), as shown previously (Kimmel et al., 1974). At this stage, however, AV stimulation applied from a loud speaker to the Petri dish containing the larvae did not elicit escape (Fig. $1 A$, bottom).

By 100 hpf, larvae had begun lying upright at rest and had started to float and to swim spontaneously. At this stage, virtually all larvae exhibited escape responses to the AV stimuli as well as to the head-touch stimuli (Fig. $1 B$ ). The overall escape trajectory of the advanced larvae was different from that of the newly-hatched larvae: the advanced larvae exhibited diminishing flexions of the tail after the initial C-bend and counter-bend, in a pattern previously referred to as adult-type escape (Kimmel et al., 1974; Eaton et al., 1977) (Fig. $1 D$, right). The time course of the acquisition of $\mathrm{AV}$-induced escape during development is depicted in Figure $1 \mathrm{E}$. The AV stimuli rarely, if ever, elicited escape before $70 \mathrm{hpf}$. The percentage of larvae exhibiting AV-induced escape dramatically increased between 80 and 100 hpf. Vibration of the Petri dish generated by the AV stimulus might activate not only AV but also tactile input in younger larvae that were lying on the bottom of the dish. However, this possibility is unlikely given that even AV stimuli at maximal intensities (peak acceleration, 500-700 m/ $\mathrm{s}^{2}$ ) did not elicit escape effectively before $70 \mathrm{hpf}$ (3 escapes of 75 trials), whereas AV stimuli at $25 \mathrm{~m} / \mathrm{s}^{2}$ were sufficient to elicit it in larvae at $>100 \mathrm{hpf}$. These results suggest that AV-induced escape was acquired after $70 \mathrm{hpf}$, whereas touch-induced escape was acquired much earlier (Fig. 1E, open squares) (For acquisition and development of tactile-induced escape, see Saint-Amant and Drapeau, 1998).

\section{Developmental change in contribution of AV input to initiation of fast escape}

The above results suggest that the tactile sensory system activated by head-touch elicits escape earlier than the inner ear or lateral line sensory systems activated by AV stimulus. We investigated the relative contribution of each sensory modality to the initiation of fast escape in larvae at different developmental stages. Tail movement in fast escape elicited by a water pulse delivered to the $\mathrm{OV}$ was observed in partially restrained (semifixed) larvae, in which the rostral body was restrained in agar while the tail was free to move (Fig. 2A). The water pulse is thought to activate the AV sensory system via stimulation of the inner ear as well as the lateral line or trigeminal sensory system through stimulation of the head skin surrounding the OV (Kohashi and Oda, 2008). The tail flip response observed in semifixed larvae exhibits the same characteristics as escape responses in unrestrained larvae (Ritter et al., 2001; Kohashi and Oda, 2008).

Water pulse stimulation of the OV elicited contralateral tail flip at every stage we tested (45-170 hpf) (Fig. 2C1). Previous studies (Burgess and Granato, 2007; Kohashi and Oda, 2008; Issa et al., 2011) have demonstrated that escapes in advanced larvae (3-10 d postfertilization) can be categorized into two kinematically distinct types: escapes with initial fast tail bending and short latency ( $<15 \mathrm{~ms}$ ) and those with slow tail bending and long latency. In the present study, 491 of 493 escapes observed in 43 larvae at 45-170 hpf started within $15 \mathrm{~ms}$, whereas only two responses had long latencies (81 and $92 \mathrm{~ms}$, respectively). Accordingly, our analysis focused on the former type of response, which we call fast escape.

We found that onset latency of the tail flip gradually decreased during development ( $p<10^{-3}$, comparison of each of two adjacent time domains using the Mann-Whitney $U$ test) (Fig. 2D; see also Fig. 4, Table 1). In particular, the minimum latency of responses in each fish decreased $\left(p<10^{-4}\right)$ from $5.8 \pm 1.0 \mathrm{~ms}$ ( 4 fish) at $45-60 \mathrm{hpf}$ to $3.0 \pm 0.0 \mathrm{~ms}$ (12 fish) at 105-170 hpf. The decrease in onset latency reflects a reduction in conduction velocity and synaptic transmission delay along the fast escape circuit from sensory inputs to motor outputs (see Discussion). In contrast, initial angular velocity of the tail flip did not change $(p>0.3): 4.2 \pm 1.0^{\circ} / \mathrm{ms}$ ( 4 fish) at $45-59 \mathrm{hpf}$ and $3.7 \pm 0.8^{\circ} \% \mathrm{~ms}$ (12 fish) at 105-170 hpf.

To elucidate which sensory modality elicits fast escape at each of several stages, we assessed the effects of eliminating each type of sensory input. First, we eliminated AV input, which is known to be the most effective activator of the M-cell in adults (for review, see Faber et al., 1991; Zottoli et al., 1995). At each developmental stage tested, fast escape was still elicited by the water pulse after lesion of the OV (Fig. 2B,C2), indicating that sensory input through the remaining tactile and/or lateral line systems is sufficient to induce fast escape. Furthermore, the initial escape trajectory in OV-lesioned fish was similar to that in intact fish [initial angular velocity: $4.1 \pm 1.1 \% \mathrm{~ms}$ at $45-59 \mathrm{hpf}$ ( $5 \mathrm{fish}$ ) and $3.5 \pm$ $0.8^{\circ} / \mathrm{ms}$ at $105-170 \mathrm{hpf}$ (13 fish); $p>0.3$ ]. Escape onset, conversely, was delayed at later developmental stages as shown in Figure $2 E$ (see also Fig. 4, Table 1): OV lesion did not affect escape onset latency in newly hatched larvae at 45-74 hpf $(p>0.3)$ but delayed it significantly after $75 \mathrm{hpf}(p<0.001)$. After that point, fast escape latencies were always $>5 \mathrm{~ms}$ in $\mathrm{OV}$-lesioned larvae. Thus, AV input is necessary to initiate fast escapes with the shortest latencies only after $75 \mathrm{hpf}$.

Next, we investigated the contribution of lateral line input, which has been demonstrated to modulate directionality and latency of sound-evoked fast escape in adult goldfish (Mirjany et al., 2011). Hair cells in lateral line neuromasts labeled with DASPEI, a styryl pyridium dye that permeates through the mechanotransduction channels into the hair cells (Gale et al., 2001; Meyers et al., 2003), were abolished by neomycin (300-500 $\mu \mathrm{M})$ (Harris et al., 2003; Murakami et al., 2003) in either newly hatched (45-63 hpf, 3 fish) or advanced (105-170 hpf, 3 fish) larvae. However, neither escape direction nor escape onset latency nor initial velocity was affected by this treatment in either stage (percentage of escapes made in contralateral direction in 8 newly hatched and 12 advanced larvae: intact, 98 and 93\%, $n=$ 108 and 133, respectively; neomycin-treated, 100 and 100\%, $n=$ 18 and 16, respectively; $p>0.3$, Fisher's exact test; latency in newly hatched and advanced larvae, $5.7 \pm 0.8$ and $5.3 \pm 2.3 \mathrm{~ms}$, respectively; initial angular velocity, $3.4 \pm 0.8$ and $4.0 \pm 1.6 \% \mathrm{~ms}$, $n=18$ and 16, respectively; $p>0.1$ ). Thus, it is unlikely that lateral line input makes a significant contribution to the initiation of larval fast escape, particularly in response to water pulses applied to the head. The effects of OV and lateral line blockade thus suggest that head-tactile input received by the trigeminal sensory system alone is sufficient to trigger fast escape in newly hatched larvae $(<75 \mathrm{hpf})$, whereas it can elicit only delayed escape at later stages of development ( $>75 \mathrm{hpf}$ ).

We next assessed the contribution of tactile input by laser ablating the sensory gV (Fig. 3A). When a water pulse was applied to the $\mathrm{OV}$ or head on the $\mathrm{gV}$-lesioned side, the tail response was never elicited in the opposite direction in newly hatched larvae (Fig. 3B, left; 45-63 hpf: percentage of contralateral response, $0 \%$; 4 fish); all tail responses $(n=18)$ were observed in the direction of the stimulus, in sharp contrast with those in intact fish. The ipsilateral tail flip observed in $\mathrm{gV}$-lesioned larvae was probably elicited by tactile input from the contralateral head skin as the head was pushed against the surrounding agar. This behav- 
A

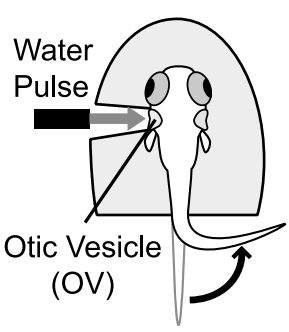

C1

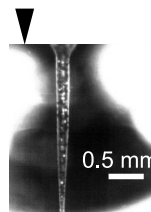

$0 \mathrm{~ms}$

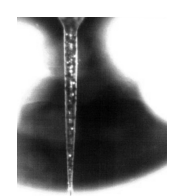

$2 \mathrm{~ms}$

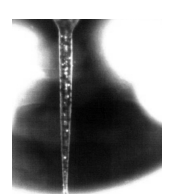

$4 \mathrm{~ms}$
B1

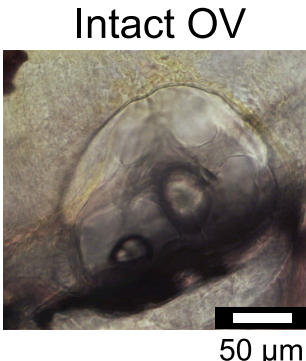

Intact (67 hpf)

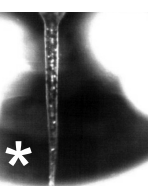

$6 \mathrm{~ms}$

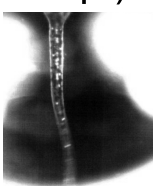

$8 \mathrm{~ms}$

\section{B2}

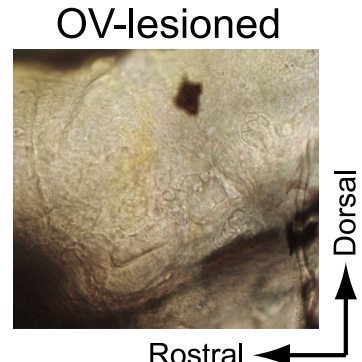

Rostral

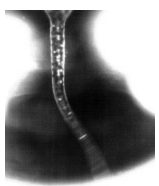

$10 \mathrm{~ms}$

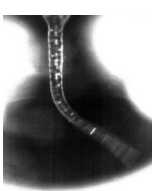

$12 \mathrm{~ms}$

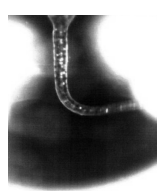

$16 \mathrm{~ms}$

C2

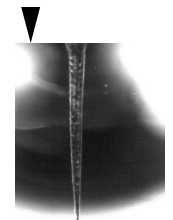

$0 \mathrm{~ms}$

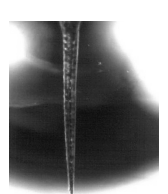

$2 \mathrm{~ms}$

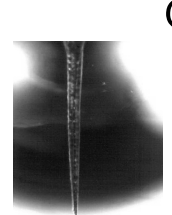

$4 \mathrm{~ms}$

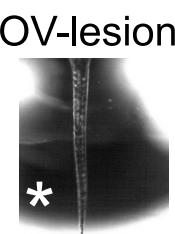

$6 \mathrm{~ms}$

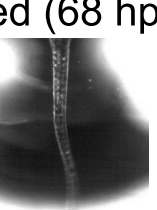

$8 \mathrm{~ms}$

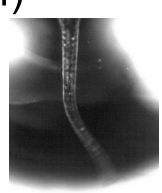

$10 \mathrm{~ms}$

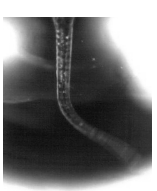

$12 \mathrm{~ms}$

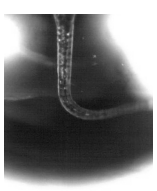

$16 \mathrm{~ms}$

D

60-74 hpf

75-89 hpf

90-104 hpf

105-170 hpf
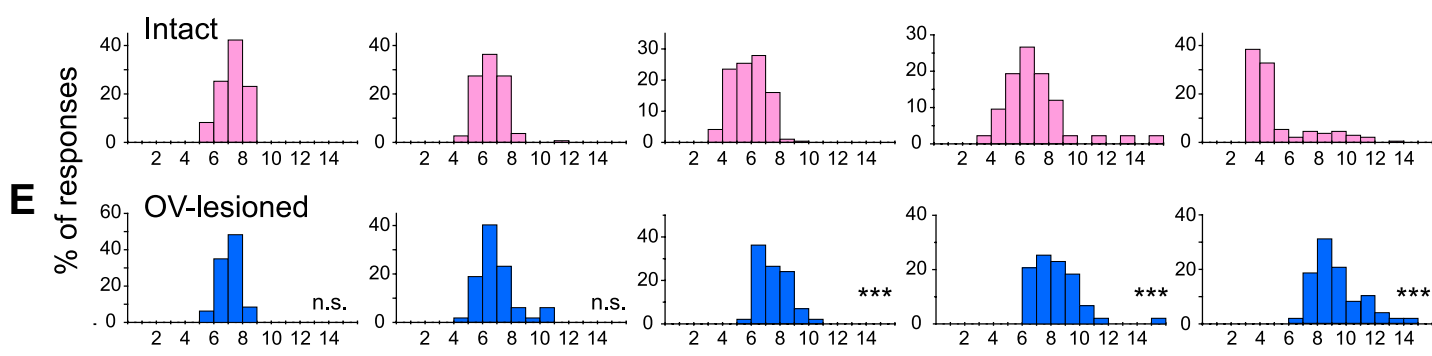

Escape onset latency (ms)

Figure 2. AV input is necessary to induce fast escape with short latency in advanced larvae. $A$, The rostral body of each larval zebrafish was embedded in agar, and tail movement was monitored with a high-speed camera. A pulsed water jet (water pulse) was applied to the OV. This stimulus is thought to activate AV, tactile, and lateral line inputs (Kohashi and Oda, 2008). $\boldsymbol{B}$, Lateral view of the OV (at $75 \mathrm{hpf}$ ) before (B1; intact OV) and after (B2; OV-lesioned) its surgical elimination. $\boldsymbol{C}$, Contralateral tail flip elicited by the water pulse delivered to intact (C1) or OV-lesioned (C2) larvae. Even after OV lesioning, newly hatched larvae showed tail flip movements similar to those of intact fish in their onset latency and initial trajectory. $\boldsymbol{D}, \boldsymbol{E}$, Frequency distributions of onset latency of tail flip responses in intact $(\boldsymbol{D})$ and OV-lesioned $(\boldsymbol{E})$ larvae at different ages as specified. Onset latencies in intact larvae $(\boldsymbol{D})$ decreased as the fish developed (see also Fig. 4C, Table 1). OV lesion (E) did not affect the onset latency before $75 \mathrm{hpf}$ (NS; $p>0.3$ ) but delayed it significantly after $75 \mathrm{hpf}\left({ }^{* * *} p<0.001\right.$ ). Note that tail flip with latency $<5$ ms was not observed in OV-lesioned larvae after 75 hpf.

Table 1. Development of escape onset latency

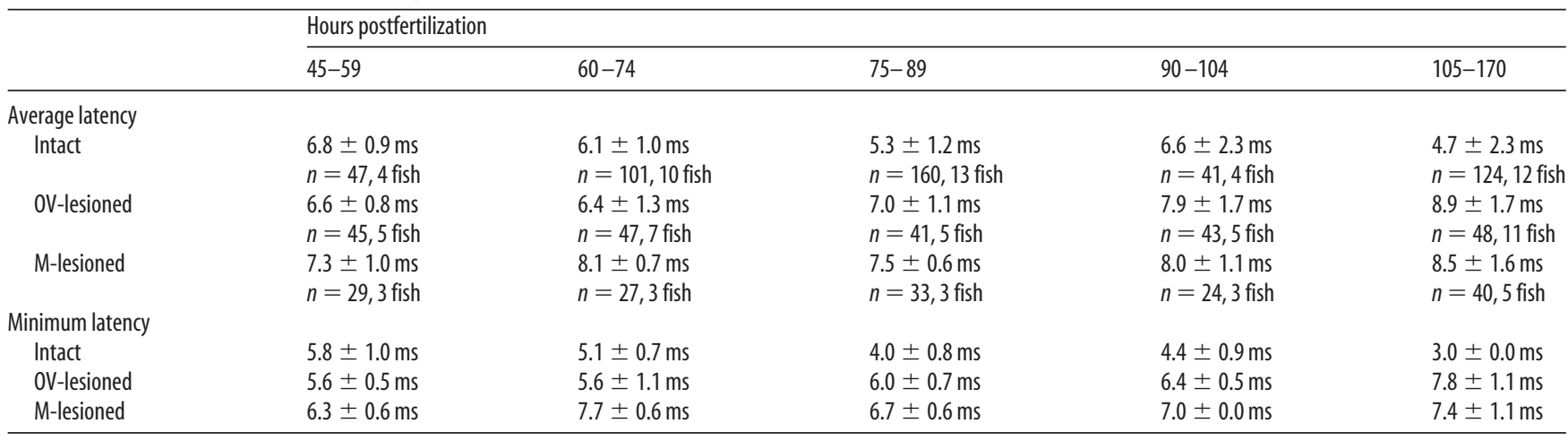

Average and minimum onset latencies of tail flip responses elicited by a water pulse delivered to the $\mathrm{OV}$ of intact, $\mathrm{OV}$-lesioned, or M-lesioned larvae in semifixed preparations, at different developmental stages. Values are reported as mean \pm SD. 
A1

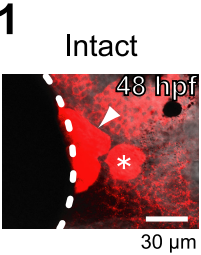

A2

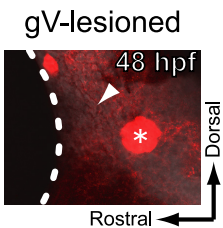

B

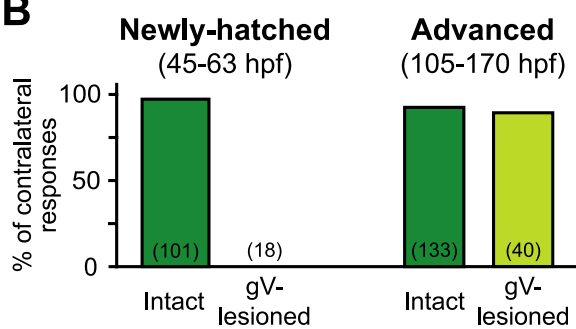

C

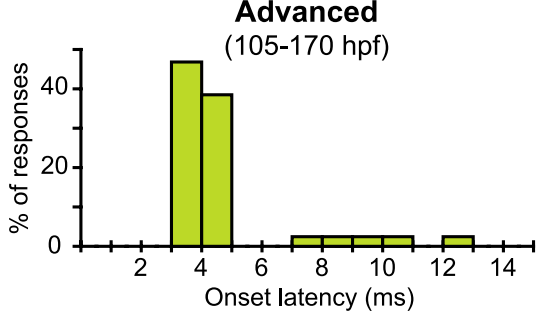

Figure 3. Head-tactile input via trigeminal nerve afferents initiates fast escape in newly hatched larvae. A, Lateral view of the gV (arrowheads). The gV cell bodies stained with anti-HuC antibody (A1, intact) were completely ablated by pulsed-laser application (A2, gV-lesioned). Note that the anterior lateral line ganglion adjacent to the $\mathrm{V} V$ remained intact (asterisk). Dotted line indicates the edge of the eye. $\boldsymbol{B}$, Directionality of tail flip response elicited by water pulse applied to the $\mathrm{OV}$ in intact or gVlesioned fish in semifixed preparations is represented by incidence of tail flips contralateral to the stimulus. In newly hatched larvae (left), virtually all tail flips of intact animals were directed contralaterally, whereas no response or only ipsilateral tail flips were observed when the stimulus was applied to the gV-lesioned side. In contrast, advanced larvae (right) with lesioned gV still showed contralateral tail flip as frequently as intact animals did. The number of tail flip responses, including ipsilateral ones, is denoted in each bar. C, Frequency distribution of onset latency of the contralateral tail flip observed in advanced larvae after gV lesion.

ioral deficit after $\mathrm{gV}$ lesion is unlikely to be caused by nonspecific damage associated with the ablation because, under unrestrained conditions, all four $\mathrm{gV}$-lesioned larvae exhibited contralateral fast escape in response to tail touch on either side or head touch on the intact side. Thus, before the acquisition of AV-induced escape $(<75 \mathrm{hpf})$, trigeminal input is necessary to initiate fast escape in response to stimulation of the head skin.

In advanced larvae (105-170 hpf), however, gV lesion had no significant effect on the directionality of fast escape (percentage of contralateral response, $90 \% ; n=40,3$ fish; $p>0.3$, Fisher's exact test) (Fig. 3B, right) or the initial angular velocity of fast escape $(4.1 \pm 0.9 \% \mathrm{~ms} ; p>0.3)$. Furthermore, unlike lesion of the $\mathrm{OV}$, ablation of the $\mathrm{gV}$ did not abolish short latency escape (3-5 $\mathrm{ms}$ ) (Fig. 3C), suggesting that head-tactile input is not necessary to induce escape with minimal latency in advanced larvae.

\section{The M-cell is already responsible for shortest-latency escape} in newly hatched larvae

It has been demonstrated in advanced larval zebrafish $(>120 \mathrm{hpf})$ that M-cell activity is necessary to initiate fast escape with short latency (Kohashi and Oda, 2008), especially in response to AV stimulation (Burgess and Granato, 2007). Here, we performed selective laser ablation of M-cells to assess their role in initiating fast escape in newly hatched larvae (Fig. $4 A, B$ ).
A1

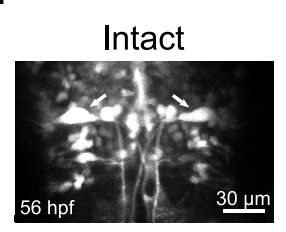

C
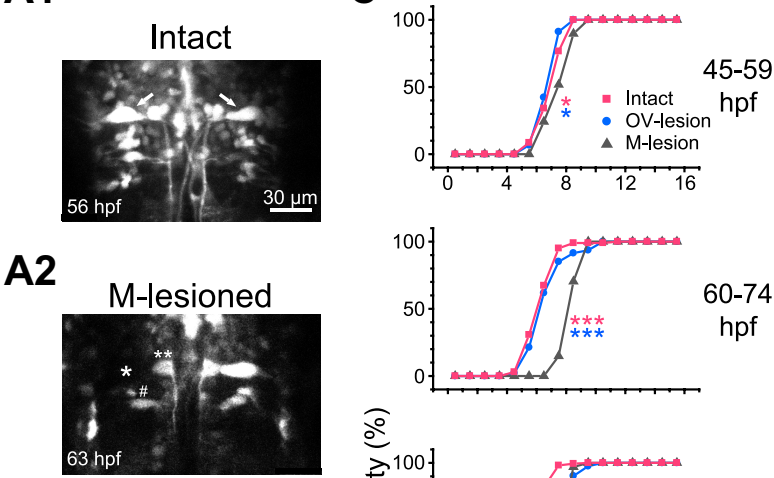

B1
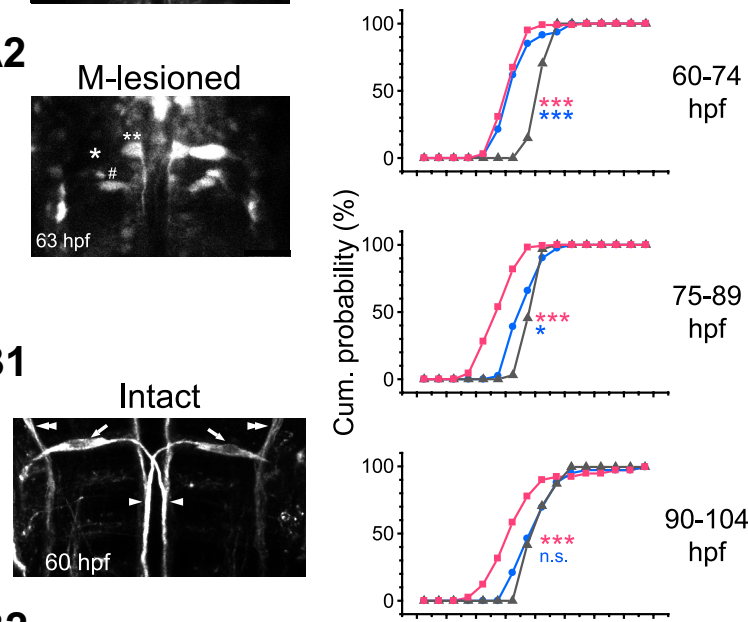

B2
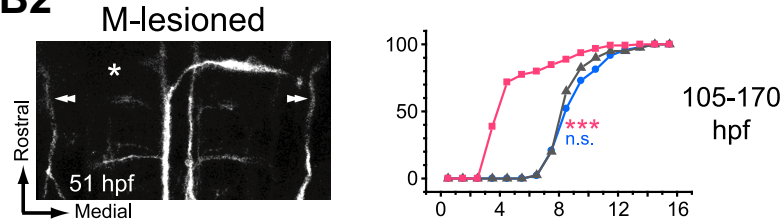

Escape onset latency (ms)

Figure 4. The M-cell is necessary to initiate fast escape with short latency. $A, B$, Selective $M$-cell ablation confirmed by GFP fluorescence $(\boldsymbol{A})$ and immunostaining $(\boldsymbol{B})$. $\boldsymbol{A}$, GFP fluorescence images of hindbrain neurons including paired M-cells (arrows) in the Tol026 transgenic zebrafish (A1). The left M-cell was irradiated with laser pulses (A2). The M-cell body showed no recovery in fluorescence (asterisk), whereas the neighboring cells (number sign and double asterisks) still exhibited fluorescence, suggesting selective photo-ablation of the M-cell. $\boldsymbol{B}$ Somata (arrows), lateral dendrites, and crossing axons (arrowheads) of both M-cells were labeled with the $3 A 10$ antibody in an intact larva (B1). After laser irradiation of the left M-cell (B2), the $3 A 10$ immunostaining of the left M-cell was not visible, whereas the descending trigeminal nerve (double arrowheads) remained intact. Scale bar in $\boldsymbol{A}$ is also applicable to $\boldsymbol{B}$. $\boldsymbol{C}$, Cumulative probability of onset latency of the tail flip response in M-lesioned fish (gray triangles) was superimposed on those for intact and OV-lesioned fish (pink squares and blue circles, respectively; reconstructed from Fig. 2, D and E). The latency was delayed significantly (pink asterisks) after ablation of the M-cell at all stages tested. Typically, responses with latencies $<6$ ms were never obtained after M-cell ablation. Note that the effect was even larger than that of OV lesion at $45-89 \mathrm{hpf}$ (blue asterisks), suggesting that the M-cell is necessary to initiate escape with short latency in response to head-tactile stimulus. After $90 \mathrm{hpf}$, lesioning the $\mathrm{OV}$ or the M-cell results in a similar delay in onset latency (NS; $p>0.3$ ), suggesting that the M-cell switches from being activated by head-tactile input to being activated by AV input in advanced larvae. ${ }^{*} p<0.05$ and ${ }^{* * *} p<0.001$.

A water pulse applied to the OV on the M-lesioned side still elicited fast escape with an initial velocity similar to that seen in intact larvae at every stage tested (45-59 hpf: $4.1 \pm 0.5 \% \mathrm{~ms}, n=$ 29,3 fish; $105-170$ hpf: $3.9 \pm 0.5^{\circ} / \mathrm{ms}, n=40,5$ fish; $\left.p>0.1\right)$. The main effect on escape observed after M-cell ablation was increased onset latency (Fig. $4 C$, Table 1). This effect was small but significant at $45-59 \mathrm{hpf}(p<0.05)$ and became more pronounced after $60 \mathrm{hpf}(p<0.001)$ (for the number of trials, see Table 1). In particular, escape starting within $6 \mathrm{~ms}$ was never observed after M-cell ablation. The effects of lesioning the M-cell or the $\mathrm{OV}$ on onset latency of fast escape are summarized in Figure $4 C$ and Table 1, demonstrating that the $\mathrm{M}$-cell is necessary 
to initiate fast escape with minimal latency at every stage tested and that the effect of OV lesion appears after $75 \mathrm{hpf}$. Considering this together with the effect of gV lesion as shown in Figure 3, we conclude that the $\mathrm{M}$-cell is required to induce fast escape with minimum latency in response to head-tactile stimuli before 75 hpf and in response to AV stimuli after $75 \mathrm{hpf}$.

\section{Effective sensory modality activating the M-cell switches from head-tactile to AV input}

To directly assess the correlation between M-cell activity and initiation of fast escape, we performed in vivo $\mathrm{Ca}^{2+}$ imaging of the M-cells during escape (Kohashi and Oda, 2008). Injecting a fluorescent $\mathrm{Ca}^{2+}$ indicator (OGB1 dextran) into the spinal cord allowed us to visualize the $\mathrm{M}$-cell attributable to retrograde transport after $64 \mathrm{hpf}$. Fluorescence response of the M-cell and associated tail movements in response to a water pulse delivered to the OV of semifixed larvae were imaged simultaneously. The fractional change in the fluorescence intensity $(\Delta F / F)$ of the $\mathrm{M}$-cell soma was compared with that elicited by an antidromic (AD) action potential at the end of the experiments, enabling us to calibrate the fluorescence change attributable to M-cell spiking. As Figure $5 \mathrm{~A}$ demonstrates, the application of electrical pulses at different stimulus intensities to the spinal cord of a newly hatched larva (69 hpf) induced a transient increase in fluorescence in the M-cell soma in an all-or-nothing manner. The constant amplitude of the suprathreshold responses at this stage (64-73 hpf; 11 cells) indicate the generation of an AD action potential, as shown previously in advanced M-cells ( $>100 \mathrm{hpf}$; Takahashi et al., 2002; Kohashi and Oda, 2008; Satou et al., 2009).

Figure 5, $B$ and $C$, exemplifies $\mathrm{Ca}^{2+}$ responses of the M-cell recorded simultaneously with a fast escape. Fast escape in newly hatched larvae ( $64-73 \mathrm{hpf} ; n=35,6$ fish) was typically accompanied by an observed increase in fluorescence in the ipsilateral M-cell soma, the amplitude of which was comparable with that associated with the AD response in the same cell. We defined a fluorescence response as an amplitude $>0.7$ times that of an $\mathrm{AD}$ spike (xAD) as a sign of orthodromic action potential of the M-cell (Kohashi and Oda, 2008; Satou et al., 2009). As shown in Figure $5 D$, most fast escapes (27 of 35 ) at this stage were accompanied by a firing of the ipsilateral M-cell (peak $\Delta F / F$, range, $0.73-2.05 \mathrm{xAD}$; average, $1.07 \pm 0.29 \mathrm{xAD} ; n=27)$. These are referred to as $\mathrm{M}$-escapes. We did not observe $\mathrm{M}$-cell firing in cases in which escape failed to occur at threshold stimulus intensity (failure, range, -0.04 to $0.32 \mathrm{xAD}$; average, $0.15 \pm 0.13 \mathrm{xAD}$; $n=5$ ), suggesting that the firing of the young M-cell is associated with initiation of fast escape in newly hatched fish as it is in mature fish (Zottoli, 1977; Eaton et al., 1981; Eaton et al., 1988; Weiss et al., 2006). In most cases, the M-cell appeared to fire only once per escape because the peak $\Delta F / F$ was $\sim 1 \mathrm{xAD}(<1.39 \mathrm{xAD}$; $n=26$ ), as in advanced M-cells (Kohashi and Oda, 2008). In one instance, however, when a relatively intense water stimulus was applied (1.3 times the behavioral threshold), we observed a large $\mathrm{Ca}^{2+}$ response with a peak $\Delta F / F$ of $2.05 \mathrm{xAD}$, suggesting the possibility that the M-cell fired more than once (Eaton et al., 1977). The remaining escapes occurred in association with only subthreshold $\mathrm{Ca}^{2+}$ increases (range, -0.17 to $0.63 \mathrm{xAD}$; average, $0.40 \pm 0.34 \mathrm{xAD} ; n=8$ ), i.e., increases too small to be considered spikes, in the same M-cell. These subthreshold increases in fluorescence may represent the $\mathrm{Ca}^{2+}$ influx associated with a postsynaptic response without spiking. Fast escapes without M-cell firing (Eaton et al., 1984; Kohashi and Oda, 2008) are referred to as non-M-escapes. M-escapes showed shorter onset latencies than non-M-escapes in young larvae (average onset latency,
$5.4 \pm 1.0, n=27$ in M-escapes and $7.1 \pm 1.8 \mathrm{~ms}, n=8$ in non-M-escapes; $p<0.01$ ), although their ranges overlapped (Fig. $5 D)$. In particular, escapes with latencies shorter than $6 \mathrm{~ms}$ were always accompanied with $\mathrm{M}$-cell firing, supporting the notion suggested by the M-lesioning experiment.

M-cells at this stage of development showed suprathreshold $\mathrm{Ca}^{2+}$ responses in association with fast escapes even after OV lesion (Fig. $5 E, F)$. Of 30 fast escapes observed in five fish (66-73 $\mathrm{hpf}), 24$ were $\mathrm{M}$-escapes $(0.74-1.45 \mathrm{xAD} ; 1.10 \pm 0.21 \mathrm{xAD})$ and six were non-M-escapes ( -0.02 to $0.56 \mathrm{xAD} ; 0.35 \pm 0.19 \mathrm{xAD})$. The onset latencies of both $\mathrm{M}$ - and non-M-escapes did not significantly change after OV lesion $(5.9 \pm 1.3$ and $6.7 \pm 0.8 \mathrm{~ms}$, respectively; $p>0.1$ ). These results suggest that $\mathrm{M}$-cells of newly hatched larvae do indeed fire in response to head-tactile stimulation and initiate fast escape with the shortest latency.

In advanced larvae (105-170 hpf), in contrast, M-escapes were abolished after OV lesion (Fig. 5: intact, G, H; OV-lesioned, $I, J)$, suggesting that AV input is necessary for the M-cell to fire, as has been reported previously for 120-240 hpf larvae (Kohashi and Oda, 2008). Of 56 fast escapes observed in 9 intact larvae, 45 were classified as M-escapes (0.75-1.52 xAD; $1.07 \pm 0.17 \mathrm{xAD})$ and 11 as non-M-escapes ( -0.02 to $0.46 \mathrm{xAD} ; 0.21 \pm 0.19 \mathrm{xAD})$. The onset latency of M-escape observed at 105-170 hpf was significantly shorter than that of non-M-escape ( $3.7 \pm 1.0$ and $7.8 \pm$ $1.5 \mathrm{~ms}$, respectively; $p<10^{-4}$ ) and was also shorter than that of M-escape in younger larvae $\left(64-73 \mathrm{hpf} ; p<10^{-4}\right)$. Delayed escape after OV lesion in advanced larvae, however, was never accompanied by a suprathreshold $\mathrm{Ca}^{2+}$ response in the M-cell (onset latency, 7-15 ms, $10.4 \pm 2.1 \mathrm{~ms}$; peak $\Delta F / F,-0.02$ to 0.42 $\mathrm{xAD}, 0.21 \pm 0.16 \mathrm{xAD} ; n=9,4$ fish), showing that only non-Mescape occurred. The developmental change in the effects of $\mathrm{OV}$ lesion suggests a change in the responsiveness of the M-cell to sensory stimuli.

Finally, we assessed the contribution of head-tactile input to $\mathrm{M}$ - and non-M-escapes in advanced larvae (Fig. 6). Fast escapes with short latencies ( $<6 \mathrm{~ms} ; 29$ of 32 escapes; $120-130$ hpf; 3 fish) were elicited as in intact fish even after $\mathrm{gV}$ lesioning, and all were associated with $\mathrm{M}$-cell firing $(0.70-1.44 \mathrm{xAD}, 1.00 \pm 0.22 \mathrm{xAD}$; onset latency, $3.4 \pm 0.5 \mathrm{~ms}$ ), suggesting that $\mathrm{AV}$ input alone is sufficient to activate $\mathrm{M}$-cells to trigger fast escapes with minimal latencies. The very few non-M-escapes that occurred after $\mathrm{gV}$ lesion (onset latency, 9 and $12 \mathrm{~ms}$; peak $\Delta F / F, 0.14$ and $0.15 \mathrm{xAD}$, respectively; 2 escapes) nevertheless appear to have been evoked by AV input. This is not surprising because M-lesioned fish still, although infrequently, exhibit delayed fast escape in response to vibratory stimulation (Kimmel et al., 1980; Zottoli et al., 1999). We did not observe any apparent $\mathrm{Ca}^{2+}$ increase (larger than 0.2 $\mathrm{xAD})$ in the $\mathrm{M}$-cells during non-M-escapes or failure trials in $\mathrm{gV}$-lesioned fish (0 of 5 non-M-escapes and failure trials; Fig. $6 A$ ), in contrast to intact fish ( 6 of 19; Fig. $5 H$ ) or OV-lesioned fish ( 5 of 12 ; Fig. $5 J$ ), implying that the trigeminal nerve afferent may still send subthreshold synaptic excitation to the M-cells in advanced larvae. Taking all this together, we conclude that the $\mathrm{M}$-cell is the primary interneuron for fast escape induced by AV input in advanced larvae. Thus, the major head-sensory modality that is necessary to activate the M-cell appears to switch from tactile to AV input in parallel with the acquisition of AV-induced escape.

\section{Discussion}

Newly hatched zebrafish before 75 hpf exhibit fast escape behavior in response to head-tactile stimuli, which are transmitted by trigeminal nerve afferents. Tactile-evoked fast escapes are mostly 


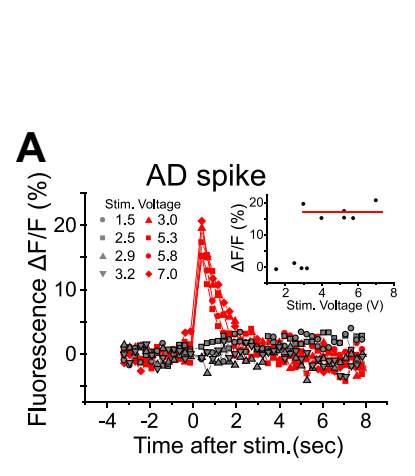

B

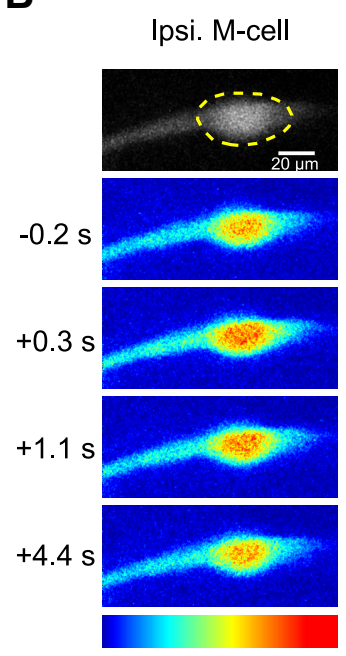

Newly-hatched

\section{Intact}

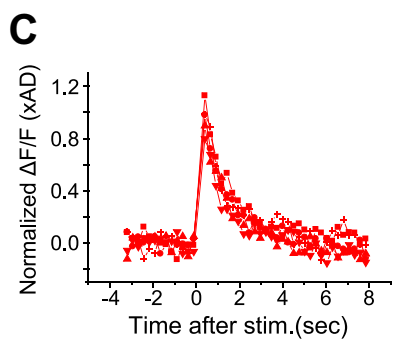

D

$64-73$ hpf

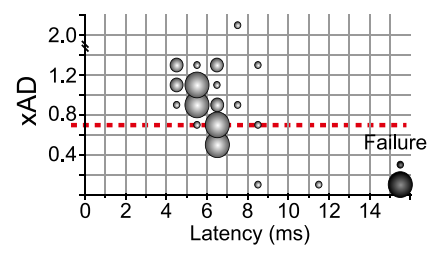

Advanced

\section{G}

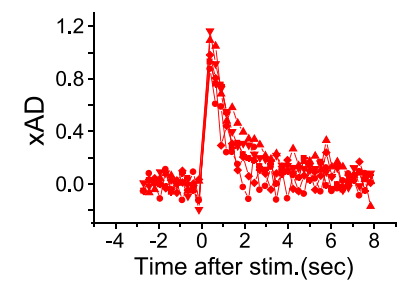

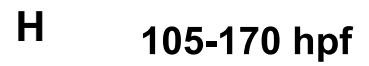

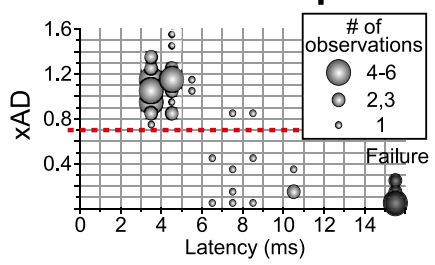

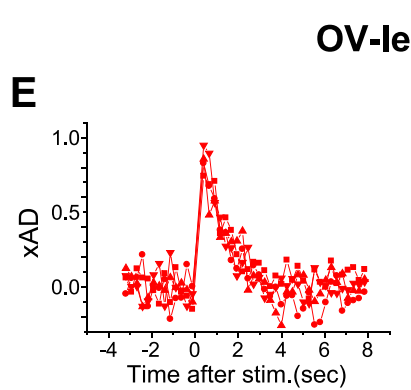

F

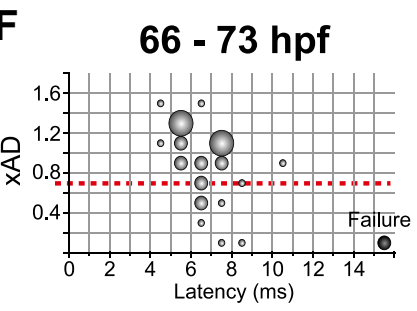

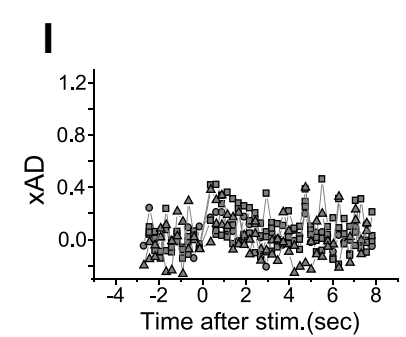

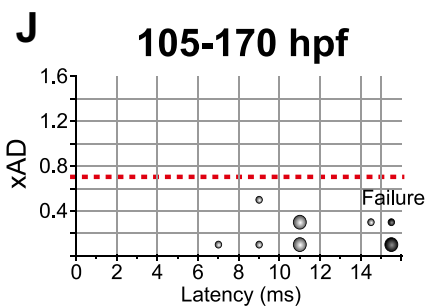

Figure 5. Spiking of the M-cell in newly hatched and advanced larvae. $A$, Fluorescence responses associated with an AD spike of an M-cell at 69 hpf in response to electrical stimulation applied to the spinal cord. Fractional changes in fluorescence intensity ( $\Delta F / F$; ordinate) of the $M$-cell soma as shown in $\boldsymbol{B}$ were plotted against the time elapsed since the stimulus (abscissa). The changes in response to different stimulus intensities (volts) occurred in an all-or-nothing manner. Inset, The constant amplitude at suprathreshold stimulus intensities (average, 17.1\%; indicated by red line, used to normalize the fluorescence responses shown in $\boldsymbol{C}$ ) is consistent with the generation of a single $A D$ spike. $\boldsymbol{B}-\boldsymbol{J}$, Fluorescence response of the $\mathrm{M}$-cell soma (dotted circle in $\boldsymbol{B}$ ) in association with fast escape. $\boldsymbol{B}$, Fluorescence response of the same $\mathrm{M}$-cell as in $\boldsymbol{A}$, observed simultaneously with fast escape elicited by a water pulse applied to the ipsilateral $0 \mathrm{~V}$. Pseudocolored fluorescence images (blue, lowest; red, highest) before $(-0.2 \mathrm{~s})$ and after $(+0.3,1.1$, and $4.2 \mathrm{~s})$ the stimulus are shown. $C$, Fluorescence responses associated with fast escape were superimposed (5 traces from the 69 hpf larva shown in $\boldsymbol{A}$ and $\boldsymbol{B}$ ). The response amplitude was normalized with the value associated with the AD response (XAD). Peak amplitudes comparable with those of the AD response ( $0.99-1.27$ XAD) suggest that the M-cell fired once during fast escape. Data points indicated by red squares were obtained from the trial shown in $\boldsymbol{B}$. $\mathbf{G}$, The M-cell in an advanced larva (132 hpf) also showed suprathreshold fluorescence response in association with fast escape ( 5 trials). $\boldsymbol{D}, \boldsymbol{H}$, Bubble chart representation of the relationship between escape onset latency (abscissa) and accompanying fluorescence response amplitude of the ipsilateral $\mathrm{M}$-cell (ordinate) at $64-73 \mathrm{hpf}(\boldsymbol{D})$ and $105-170 \mathrm{hpf}(\boldsymbol{H})$. The size of the bubbles represents the number of observations (inset in $\boldsymbol{H}$ is also applicable to $\boldsymbol{D}, \boldsymbol{F}$, and $\boldsymbol{J}$ ) in each bin (indicated by gray lines). Response above the threshold (red dotted line; $0.7 \mathrm{xAD}$ ) was thought to represent firing, as demonstrated previously (Kohashi and 0 da, 2008). $\boldsymbol{E}, \boldsymbol{I}$, Suprathreshold and subthreshold fluorescence responses of the M-cell, associated with fast escape after OV lesion, in a newly hatched larva ( $\boldsymbol{E}, 4$ responses from a $73 \mathrm{hpf}$ larva) and advanced larvae (I, 5 traces from $3130-147$ hpf larvae), respectively. $F, J$, Bubble chart representation of the relationship between M-cell activity and escape latency in OV-lesioned larvae. In contrast to newly hatched larvae $(\boldsymbol{F}, 66-73 \mathrm{hpf})$, advanced larvae $(\boldsymbol{J}, 105-170 \mathrm{hpf})$ never showed suprathreshold response in the M-cell after OV lesion.

associated with M-cell firing. After $75 \mathrm{hpf}, \mathrm{M}$-cells begin to fire in response to AV rather than tactile input. In both stages, M-cell firing is necessary to induce fast escape with minimal latency.

\section{Switch from tactile to AV input as primary activator of the M-cell}

The present study shows that M-cell firing is necessary for initiating escape with minimal latency at every stage studied (45-170 hpf) (Fig. 4), yet the major sensory modality activating the M-cell switches effectively from tactile input in newly hatched larvae $(<75 \mathrm{hpf})$ to AV input in advanced larvae (105-170 hpf) (Figs. 5-7). Early development of AV input to the M-cell has been investigated both morphologically and physiologically. The statoacoustic nerve (VIIIn) afferent pathway from inner-ear hair cells to the $\mathrm{M}$-cell forms well before hatching. The hair cells in the OV and the statoacoustic ganglion neurons appear before $24 \mathrm{hpf}$ (Haddon and Lewis, 1996; Tanimoto et al., 2011). The earliest contact of the VIIIn on the lateral dendrite of the M-cell occurs at 
23 hpf (Kimmel et al., 1990). Peripheral projections from the VIIIn connect with hair cells before $27 \mathrm{hpf}$ (Tanimoto et al., 2009). Sound-evoked postsynaptic current (PSC) in the $\mathrm{M}$-cell is first observed at $46 \mathrm{hpf}$, subsequently increasing in amplitude while decreasing in onset latency (Tanimoto et al., 2009, their Fig. 1).

Compared with the acquisition of auditory responsiveness of the M-cell, AV-induced escape (Fig. 1) and the effect of OV deprivation on escape initiation (Fig. 2) appear late in development ( $>75 \mathrm{hpf}$ ), indicating that additional development of AV input is required for the $\mathrm{M}$-cell to initiate fast escape after this acquisition. Development of the inner ear, especially the doubling of the number of hair cells in the OV between 65 and 90 hpf (Haddon and Lewis, 1996), may enable AV input to drive M-cells to fire after $75 \mathrm{hpf}$. This may also underlie the acquisition of other AVinduced behaviors, because both vestibulo-oculomotor reflex (Easter and Nicola, 1997) and postural equilibrium (Riley and Moorman, 2000) also appear during this period (3-4 d postfertilization) in zebrafish.

At 75-89 hpf, the onset latency of fast escape was delayed by M-cell lesion more than by OV lesion (Fig. 4). In contrast, in advanced larvae, the two types of lesions delayed escape onset similarly (>90 hpf; Fig. 4) and the M-cell never fired after OV lesion (>105 hpf; Fig. 5). Together, these results suggest that trigeminal input is still effective at driving the M-cell to fire at the intermediate stage (75-89 hpf), although it gradually becomes less effective throughout the day after the acquisition of AV-induced escape. Eventually, the M-cell becomes the primary interneuron for AV-induced fast escape (Kimmel et al., 1980; Burgess and Granato, 2007; Kohashi and Oda, 2008; Issa et al., 2011).

We propose that the following mechanisms underlie the decreasing effectiveness of trigeminal input in M-cell firing. The trigeminal nerves run caudally thorough the brainstem, thus approaching the lateral dendrite of the M-cell perpendicularly, synapsing onto it at a small contact region (Kimmel et al., 1981). Relatively weak excitatory synaptic currents via the small trigeminal nerve contact can drive the young $\mathrm{M}$-cell to fire attributable to high input resistance, but this small current may become insufficient as the $\mathrm{M}$-cell grows larger (Kimmel et al., 1981) and its input resistance decreases dramatically (M. Tanimoto and Y. Oda, unpublished observations). Conversely, fibers in the trigeminal nerves also synapse onto the dendrites of smaller RSNs (Kimmel et al., 1985). This trigeminal input is sufficient to fire the small RSNs (O'Malley et al., 1996; Gahtan et al., 2002) and initiate non-M-escape in advanced larvae (Kohashi and Oda, 2008) because of their small size and high input resistance.

We propose several behavioral advantages of early acquisition and late suppression of tactile-evoked M-escape. Given that the $\mathrm{M}$-cell is the earliest descending neuron to develop (Mendelson, 1986a,b) and receives the trigeminal afferent fiber contact as the first sensory input (Kimmel et al., 1990) in embryo, activating the $\mathrm{M}$-cell with early-developing tactile input allows larvae to acquire escape behavior at the earliest possible developmental stage. However, tactile-evoked M-escape becomes less useful as fish
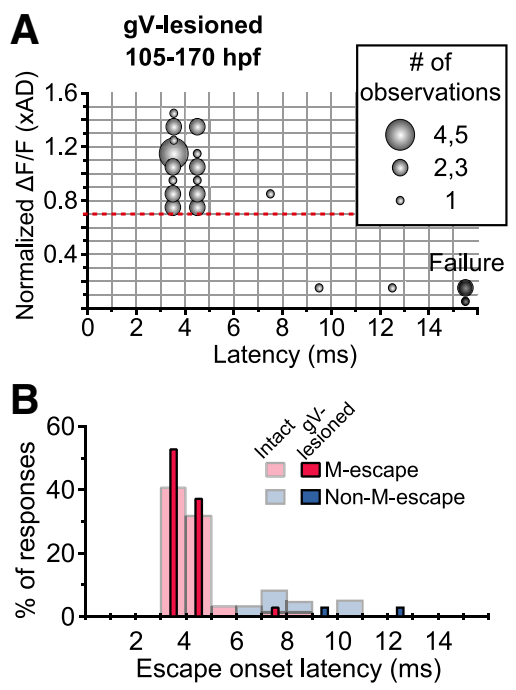

Figure 6. Head-tactile input is not necessary to induce M-escape in advanced larvae. $\boldsymbol{A}$, Bubble chart representation of the relationship between escape onset latency and accompanying fluorescence response amplitude of the ipsilateral M-cells in gV-lesioned larvae at 105-170 hpf. $\boldsymbol{B}$, Frequency distribution of onset latencies of $\mathrm{M}$ - and non-M-escape (red and blue, respectively) in intact (pale-colored) and gV-lesioned (vivid-colored) larvae.

Figure 7. Schematic drawings of fast escape circuit before and after acquisition of AV-induced escape, reflecting developmental events described in Discussion. Before $75 \mathrm{hpf}$, head-tactile input through the trigeminal nerve initiates both $\mathrm{M}$ - and non-M-escape. $75 \mathrm{hpf}$, developing AV input becomes effective to fire the M-cell and AV-induced escape is acquired. In the meantime, $\mathrm{M}$-cell is necessary to initiate escape with minimal latency. Non-active or ineffective pathways are colored in gray. Thicker descending axons from the M-cells or non-M-cells represent shorter conduction times.

develop: after acquisition of AV-induced M-escape, larvae swim actively in schools (Engeszer et al., 2007). If tactile-evoked M-escape occurs in response to collisions with other fish, this may lead the fish to miss its prey during competing for food or to jump out of its school, resulting in a high risk of predation (Stankowich, 2003). Furthermore, suppressing tactile-evoked M-escape by decreasing the effect of tactile input on M-cells, not by reducing excitability or behavioral impact of $\mathrm{M}$-cells, allows fish to retain behavioral sensitivity to aversive auditory input even in schooling situations rich with non-aversive tactile input.

Conversely, mechanosensory stimuli applied to the tail also may elicit M-escape in both newly hatched and advanced larvae (Eaton et al., 1984; O'Malley et al., 1996; Kohashi and Oda, 2008; Low et al., 2010). Tactile input via Rohon-Beard or dorsal root ganglion mechanosensory neurons is thought to mediate tail-directed stimuli and activate M-cells. Around hatching, embryonic Rohon-Beard neurons gradually disappear through ap- 
optosis and dorsal root ganglion neurons assume their role (Williams et al., 2000; Reyes et al., 2004). Additionally, the posterior lateral line system starts to innervate the tail after hatching (Ledent, 2002). Therefore, unlike head sensory systems which persist through development, tail sensory input for M-cells is replaced by late-developing sensory systems.

\section{Reduction of onset latency associated with M-cell development}

In intact larvae, the minimum onset latency of fast escape that are Mauthner-initiated responses decreased from $\sim 6 \mathrm{~ms}$ at $45-59$ hpf to $\sim 3 \mathrm{~ms}$ after $105 \mathrm{hpf}$ (Table 1). Accordingly, signal conduction delays along the M-escape pathway decrease during development. Certain steps in signal transmission that are common to tactile- and AV-induced M-escape may speed up during development: (1) the stage from PSC onset to M-cell firing, (2) conduction of the action potential along the $\mathrm{M}$-axon to the spinal cord, (3) the stage from the spiking of the M-cell presynaptic terminals to that of the trunk motoneurons (for review, see Fetcho, 1991), and (4) excitation-contraction coupling in the muscles.

As for the first step, morphological growth of the lateral dendrite of the M-cell, changing the cell shape from spherical to more cylindrical (Kimmel et al., 1981), potentially shortens the apparent time constant of the soma-dendritic membrane and reduces spike latency from the onset of depolarizing postsynaptic potentials (Rall, 1969). In addition, the M-cell membrane expresses low-voltage-gated potassium channels (Nakayama and Oda, 2004). Developmental increases in potassium currents, as in the auditory brainstems of higher vertebrates (Howard et al., 2007; Nakamura and Takahashi, 2007), will also help decrease the membrane time constant at the depolarizing phase before action potential generation (Fukui and Ohmori, 2004; Gittelman and Tempel, 2006).

As for the second step, conduction velocity of the growing M-axon increases (Eaton et al., 1977) with axon thickening (Kimmel, 1972). We estimate the spike conduction times along the $\mathrm{M}$-axon from the cell body to mid-spinal cord to be 1.3 and 0.4 $\mathrm{ms}$ at $45-59$ and $105 \mathrm{hpf}$, respectively, on the basis of conduction velocities (1.1 and $3.7 \mathrm{~m} / \mathrm{s}$, respectively; from Eaton et al., 1977) and spinal length (1.4 and $1.6 \mathrm{~mm}$, respectively; from M-cell body to the cloaca where we measured tail movement). This explains as much as one-third of the observed decrease in latency.

The third and fourth steps may also decrease in latency during development. Development of AV input to the M-cell also potentially decreases escape latency by advancing $\mathrm{M}$-cell firing.

\section{M-cells as a model for studying neuronal basis of sensorimotor development}

Because AV-induced behaviors are typically acquired later than tactile-induced ones among vertebrates (Fox, 1964, 1965; Decker, 1967; Villablanca and Olmstead, 1979), the unequivocal identifiability and distinct behavioral role of M-cells make them a unique model for studying the cellular mechanisms underlying the delayed acquisition of AV-induced behaviors. The M-cell is one of the RSNs, which together constitute a phylogenetically conserved descending system across vertebrates (Nieuwenhuys et al., 1998; Butler and Hodos, 2005) that integrates sensory inputs to generate spinal motor commands (Rossignol et al., 2006; Grillner et al., 2008). In addition, the neuronal components and basic characteristics of fast escape in teleosts are strikingly similar to those of acoustic startle in higher vertebrates (Korn and Faber, 1996; Burgess and Granato, 2007). Thus, the switch in the effec- tive sensory input to RSNs that elicits teleost fast escape may serve as a common physiological process underlying early sensorimotor development of vertebrates: developing nervous systems expand their ability to respond to a variety of sensory stimuli by dedicating a subcomponent of the preexisting sensorimotor circuit to late-developing modalities. Particularly in teleost fishes, such as zebrafish and goldfish, so-called hearing specialists (Popper and Fay, 1999), M-cells may take the decisive role in AV-induced fast escape because of massive AV input onto their lateral dendrites, whereas other RSNs take on tactile-evoked fast escape.

\section{References}

Allendoerfer KL, Shatz CJ (1994) The subplate, a transient neocortical structure: its role in the development of connections between thalamus and cortex. Annu Rev Neurosci 17:185-218.

Burgess HA, Granato M (2007) Sensorimotor gating in larval zebrafish. J Neurosci 27:4984-4994.

Butler AB, Hodos W (2005) Comparative vertebrate neuroanatomy: evolution and adaptation, Ed 2. Hoboken, NJ: Wiley.

Daw NW (2006) Visual development, Ed 2. New York: Springer.

Decker JD (1967) Motility of the turtle embryo, Chelydra serpentina (Linne). Science 157:952-954.

Domenici P, Blake R (1997) The kinematics and performance of fish faststart swimming. J Exp Biol 200:1165-1178.

Easter SS Jr, Nicola GN (1997) The development of eye movements in the zebrafish (Danio rerio). Dev Psychobiol 31:267-276.

Eaton RC, Farley RD (1973) Development of the Mauthner neurons in embryos and larvae of the zebrafish, Brachydanio rerio. Copeia 674-682.

Eaton RC, Farley RD, Kimmel CB, Schabtach E (1977) Functional development in the Mauthner cell system of embryos and larvae of the zebra fish. J Neurobiol 8:151-172.

Eaton RC, Lavender WA, Wieland CM (1981) Identification of Mauthnerinitiated response patterns in goldfish: evidence from simultaneous cinematography and electrophysiology. J Comp Physiol A Neuroethol Sens Neural Behav Physiol 144:521-531.

Eaton RC, Nissanov J, Wieland CM (1984) Differential activation of Mauthner and non-Mauthner startle circuits in the zebrafish: implications for functional substitution. J Comp Physiol A Neuroethol Sens Neural Behav Physiol 155:813-820.

Eaton RC, DiDomenico R, Nissanov J (1988) Flexible body dynamics of the goldfish C-start: implications for reticulospinal command mechanisms. J Neurosci 8:2758-2768.

Engeszer RE, Barbiano LA, Ryan MJ, Parichy DM (2007) Timing and plasticity of shoaling behaviour in the zebrafish, Danio rerio. Anim Behav 74:1269-1275.

Faber DS, Korn H, Lin JW (1991) Role of medullary networks and postsynaptic membrane properties in regulating Mauthner cell responsiveness to sensory excitation. Brain Behav Evol 37:286-297.

Fetcho JR (1991) Spinal network of the Mauthner cell. Brain Behav Evol 37:298-316.

Fox WM (1964) The ontogeny of behaviour and neurologic responses in the dog. Anim Behav 12:301-310.

Fox WM (1965) Reflex-ontogeny and behavioural development of the mouse. Anim Behav 13:234-241.

Fukui I, Ohmori H (2004) Tonotopic gradients of membrane and synaptic properties for neurons of the chicken nucleus magnocellularis. J Neurosci 24:7514-7523.

Gahtan E, Sankrithi N, Campos JB, O’Malley DM (2002) Evidence for a widespread brain stem escape network in larval zebrafish. J Neurophysiol 87:608-614.

Gale JE, Marcotti W, Kennedy HJ, Kros CJ, Richardson GP (2001) FM1-43 dye behaves as a permeant blocker of the hair-cell mechanotransducer channel. J Neurosci 21:7013-7025.

Gittelman JX, Tempel BL (2006) Kv1.1-containing channels are critical for temporal precision during spike initiation. J Neurophysiol 96:1203-1214.

Grillner S, Wallén P, Saitoh K, Kozlov A, Robertson B (2008) Neural bases of goal-directed locomotion in vertebrates-an overview. Brain Res Rev 57:2-12.

Haddon C, Lewis J (1996) Early ear development in the embryo of the zebrafish, Danio rerio. J Comp Neurol 365:113-128.

Harris JA, Cheng AG, Cunningham LL, MacDonald G, Raible DW, Rubel EW 
(2003) Neomycin-induced hair cell death and rapid regeneration in the lateral line of zebrafish (Danio rerio). J Assoc Res Otolaryngol 4:219-234.

Hatta K (1992) Role of the floor plate in axonal patterning in the zebrafish CNS. Neuron 9:629-642.

Howard MA, Burger RM, Rubel EW (2007) A developmental switch to GABAergic inhibition dependent on increases in Kv1-type $\mathrm{K}^{+}$currents. J Neurosci 27:2112-2123.

Issa FA, O'Brien G, Kettunen P, Sagasti A, Glanzman DL, Papazian DM (2011) Neural circuit activity in freely behaving zebrafish (Danio rerio). J Exp Biol 214:1028-1038.

Jontes JD, Buchanan J, Smith SJ (2000) Growth cone and dendrite dynamics in zebrafish embryos: early events in synaptogenesis imaged in vivo. Nat Neurosci 3:231-237.

Katz LC, Crowley JC (2002) Development of cortical circuits: lessons from ocular dominance columns. Nat Rev Neurosci 3:34-42.

Kimmel CB (1972) Mauthner axons in living fish larvae. Dev Biol 27:272-275.

Kimmel CB, Patterson J, Kimmel RO (1974) The development and behavioral characteristics of the startle response in the zebra fish. Dev Psychobiol 7:47-60.

Kimmel CB, Eaton RC, Powell SL (1980) Decreased fast-start performance of zebrafish larvae lacking Mauthner neurons. J Comp Physiol A Neuroethol Sens Neural Behav Physiol 140:343-350.

Kimmel CB, Sessions SK, Kimmel RJ (1981) Morphogenesis and synaptogenesis of the zebrafish Mauthner neuron. J Comp Neurol 198:101-120.

Kimmel CB, Metcalfe WK, Schabtach E (1985) T reticular interneurons: a class of serially repeating cells in the zebrafish hindbrain. J Comp Neurol 233:365-376.

Kimmel CB, Hatta K, Metcalfe WK (1990) Early axonal contacts during development of an identified dendrite in the brain of the zebrafish. Neuron 4:535-545.

Kimmel CB, Ballard WW, Kimmel SR, Ullmann B, Schilling TF (1995) Stages of embryonic development of the zebrafish. Dev Dyn 203:253-310.

Kohashi T, Oda Y (2008) Initiation of Mauthner- or non-Mauthnermediated fast escape evoked by different modes of sensory input. J Neurosci 28:10641-10653.

Korn H, Faber DS (1996) Escape behavior-brainstem and spinal cord circuitry and function. Curr Opin Neurobiol 6:826-832.

Ledent V (2002) Postembryonic development of the posterior lateral line in zebrafish. Development 129:597-604.

Liu KS, Fetcho JR (1999) Laser ablations reveal functional relationships of segmental hindbrain neurons in zebrafish. Neuron 23:325-335.

Low SE, Zhou W, Choong I, Saint-Amant L, Sprague SM, Hirata H, Cui WW, Hume RI, Kuwada JY (2010) $\mathrm{Na}(\mathrm{V}) 1.6 \mathrm{a}$ is required for normal activation of motor circuits normally excited by tactile stimulation. Dev Neurobiol 70:508-522.

Mendelson B (1986a) Development of reticulospinal neurons of the zebrafish. I. Time of origin. J Comp Neurol 251:160-171.

Mendelson B (1986b) Development of reticulospinal neurons of the zebrafish. II. Early axonal outgrowth and cell body position. J Comp Neurol 251:172-184.

Meyers JR, MacDonald RB, Duggan A, Lenzi D, Standaert DG, Corwin JT, Corey DP (2003) Lighting up the senses: FM1-43 loading of sensory cells through nonselective ion channels. J Neurosci 23:4054-4065.

Mirjany M, Preuss T, Faber DS (2011) Role of the lateral line mechanosensory system in directionality of goldfish auditory evoked escape response. J Exp Biol 214:3358-3367.

Murakami SL, Cunningham LL, Werner LA, Bauer E, Pujol R, Raible DW, Rubel EW (2003) Developmental differences in susceptibility to neomycin-induced hair cell death in the lateral line neuromasts of zebrafish (Danio rerio). Hear Res 186:47-56.

Nakamura Y, Takahashi T (2007) Developmental changes in potassium currents at the rat calyx of Held presynaptic terminal. J Physiol 581:1101-1112.

Nakayama H, Oda Y (2004) Common sensory inputs and differential excitability of segmentally homologous reticulospinal neurons in the hindbrain. J Neurosci 24:3199-3209.
Nieuwenhuys R, ten Donkelaar HJ, Nicholson C (1998) The central nervous system of vertebrates. Berlin: Springer.

O'Malley DM, Kao YH, Fetcho JR (1996) Imaging the functional organization of zebrafish hindbrain segments during escape behaviors. Neuron 17:1145-1155.

Popper AN, Fay RR (1999) The auditory periphery in fishes. In: Comparative hearing: fish and amphibians (Fay RR, Popper AN, eds), pp 43-100. New York: Springer.

Rall W (1969) Time constants and electrotonic length of membrane cylinders and neurons. Biophys J 9:1483-1508.

Reyes R, Haendel M, Grant D, Melancon E, Eisen JS (2004) Slow degeneration of zebrafish Rohon-Beard neurons during programmed cell death. Dev Dyn 229:30-41.

Riley BB, Moorman SJ (2000) Development of utricular otoliths, but not saccular otoliths, is necessary for vestibular function and survival in zebrafish. J Neurobiol 43:329-337.

Ritter DA, Bhatt DH, Fetcho JR (2001) In vivo imaging of zebrafish reveals differences in the spinal networks for escape and swimming movements. J Neurosci 21:8956-8965.

Rossignol S, Dubuc R, Gossard JP (2006) Dynamic sensorimotor interactions in locomotion. Physiol Rev 86:89-154.

Rubel EW, Popper AN, Fay RR (1998) Development of the auditory system. New York: Springer.

Sagasti A, Guido MR, Raible DW, Schier AF (2005) Repulsive interactions shape the morphologies and functional arrangement of zebrafish peripheral sensory arbors. Curr Biol 15:804-814.

Saint-Amant L, Drapeau P (1998) Time course of the development of motor behaviors in the zebrafish embryo. J Neurobiol 37:622-632.

Satou C, Kimura Y, Kohashi T, Horikawa K, Takeda H, Oda Y, Higashijima S (2009) Functional role of a specialized class of spinal commissural inhibitory neurons during fast escapes in zebrafish. J Neurosci 29:6780-6793.

Stankowich T (2003) Marginal predation methodologies and the importance of predator preferences. Anim Behav 66:589-599.

Takahashi M, Narushima M, Oda Y (2002) In vivo imaging of functional inhibitory networks on the Mauthner cell of larval zebrafish. J Neurosci 22:3929-3938.

Tanimoto M, Ota Y, Horikawa K, Oda Y (2009) Auditory input to CNS is acquired coincidentally with development of inner ear after formation of functional afferent pathway in zebrafish. J Neurosci 29:2762-2767.

Tanimoto M, Ota Y, Inoue M, Oda Y (2011) Origin of inner ear hair cells: morphological and functional differentiation from ciliary cells into hair cells in zebrafish inner ear. J Neurosci 31:3784-3794.

Uemura O, Okada Y, Ando H, Guedj M, Higashijima S, Shimazaki T, Chino $\mathrm{N}$, Okano H, Okamoto H (2005) Comparative functional genomics revealed conservation and diversification of three enhancers of the isll gene for motor and sensory neuron-specific expression. Dev Biol 278:587-606.

Villablanca JR, Olmstead CE (1979) Neurological development of kittens. Dev Psychobiol 12:101-127.

Weiss SA, Zottoli SJ, Do SC, Faber DS, Preuss T (2006) Correlation of C-start behaviors with neural activity recorded from the hindbrain in free-swimming goldfish (Carassius auratus). J Exp Biol 209:4788-4801.

Westerfield M (2007) The zebrafish book: a guide for the laboratory use of zebrafish (Danio rerio), Ed 5. Eugene, OR: University of Oregon.

Williams JA, Barrios A, Gatchalian C, Rubin L, Wilson SW, Holder N (2000) Programmed cell death in zebrafish rohon beard neurons is influenced by TrkC1/NT-3 signaling. Dev Biol 226:220-230.

Zottoli SJ (1977) Correlation of the startle reflex and Mauthner cell auditory responses in unrestrained goldfish. J Exp Biol 66:243-254.

Zottoli SJ, Bentley AP, Prendergast BJ, Rieff HI (1995) Comparative studies on the Mauthner cell of teleost fish in relation to sensory input. Brain Behav Evol 46:151-164

Zottoli SJ, Newman BC, Rieff HI, Winters DC (1999) Decrease in occurrence of fast startle responses after selective Mauthner cell ablation in goldfish (Carassius auratus). J Comp Physiol A Neuroethol Sens Neural Behav Physiol 184:207-218. 